\title{
The expression of insulin-like growth factor-1 in senior patients with diabetes and dementia
}

\author{
YAN-LING ZHOU ${ }^{1 *}$, SHU-QING LIU²*, BIN YUAN ${ }^{3}$ and NING LU ${ }^{4}$ \\ ${ }^{1}$ Department of Neurology, Yantai Affiliated Hospital of Binzhou Medical University, Yantai, Shandong 264003; \\ ${ }^{2}$ Department of Neurology, Linglong Yingcheng Hospital, Zhaoyuan, Shandong 265400; ${ }^{3}$ Department of Neurology, \\ Affiliated Hospital of Heze Medical College, Heze, Shandong 274000; ${ }^{4}$ Department of Geriatric Medicine, \\ Yantai Affiliated Hospital of Binzhou Medical University, Yantai, Shandong 264003, P.R. China
}

Received May 16, 2016; Accepted October 31, 2016

DOI: $10.3892 /$ etm.2016.3961

\begin{abstract}
This study was conducted to investigate the expression of insulin-like growth factor-1 (IGF-1) in elderly patients with diabetes and dementia and to analyze the expression mechanism. A total of 30 senior patients with diabetes and dementia (group A), 30 senior patients with dementia but no diabetes (group B), 30 senior patients with diabetes but no dementia (group C), and 30 healthy seniors (group D) were continuously selected. The ELISA method was used to test the level of serum IGF-1, $\beta$-amyloid peptide $(A \beta)$ and the phosphorylation of immunohistochemical staining of microtubule associated protein (tau protein). Western blot analysis was utilized to test the level of prion protein $(\mathrm{PrP})$, forkhead transcription factor $\mathrm{O}$ (FOXO) subfamily protein, $\mathrm{p}-\mathrm{PI} 3 \mathrm{~K}$ and p-Akt. The levels of IGF-1, A $\beta$, tau protein positive rate, PrP, FOXO protein, $\mathrm{p}-\mathrm{PI} 3 \mathrm{~K}$, and $\mathrm{p}-\mathrm{Akt}$ in group A were significantly higher than that in group $\mathrm{B}$, which was higher than in groups $\mathrm{C}$ and $\mathrm{D}$. The results between groups $\mathrm{A}$ and $\mathrm{B}$, but not groups $C$ and $D$, were statistically significant $(P<0.05)$. IGF-1 was highly expressed in senior patients with diabetes and dementia. Thus, IGF-1 can adjust the expression of PrP and FOXO through p-PI3K/Akt pathway and further impact the formation of $A \beta$ and tau protein, leading to dementia.
\end{abstract}

\section{Introduction}

Alzheimer's disease (AD) is related to age and is a neurodegenerative disease featuring progressive cognitive disorder

Correspondence to: Dr Ning Lu, Department of Geriatric Medicine, Yantai Affiliated Hospital of Binzhou Medical University, 717 Jinbu street, Yantai, Shandong 264003, P.R. China

E-mail: ning_lu1@163.com

*Contributed equally

Key words: insulin-like growth factor-1, diabetes, dementia, $\beta$-amyloid peptide, microtubule associated protein, prion protein, forkhead transcription factor $\mathrm{O}$, and PI3K/Akt and memory damage. Since diabetes can increase the risk of vascular dementia and AD, some scholars regard AD as another type of diabetes (1). Rasgon and Jarvik (2) found that cognitive disorders or AD incidence rates were 2- to 3-fold higher in patients with type 2 diabetes mellitus (T2DM) than those in control group. Thus, T2DM was found to be a risk factor in cognitive disorders among seniors. The main pathologic features of AD include senile plaques, neurofibrillary tangles, neuro-reduction and insulin neuro-transduction involved in its metabolic pathway (2).

Insulin-like growth factor-1 (IGF-1) is an important neurotrophic factor and its receptor IGF-1R is prevalently expressed in the nervous system (3). IGF-1 can impact the elimination of $\beta$-amyloid peptide $(\mathrm{A} \beta)$ and the phosphorylation of microtubule associated protein (tau), which is related to PI3K/Akt and MAPK/ERK1/2 signal pathways (4). Forkhead transcription factor O (FOXO) subfamily protein, an important downstream responsive molecule in IGF-1 signal pathway, is modified and adjusted by the post-translational modification in the PI3K/Akt pathway (5). Most studies conducted are centered on AD animal models while few involve in-clinic observation. Therefore, this study serves as a reference to clinical diagnosis and treatment by examining whether the IGF-1 expression in different groups of seniors is related to diabetes and AD, and the possible action mechanism.

\section{Patients and methods}

Subject information. A total of 30 senior patients who were admitted to and diagnosed by our hospital with diabetes and $\mathrm{AD}$ (group A), 30 with AD but no diabetes (group B), 30 with diabetes but no AD (group C), and 30 healthy seniors (group D) were continuously selected from June 2013 to January 2016. The selection criteria for the study were: i) Age, $\geq 65$; and ii) meet WHO's T2DM diagnosis standard and Chicago AD diagnosis standard, including pre-clinical phase and dementia phase. The exclusion criteria included: i) Serious diabetes complications, such as eye-ground retinal hemorrhage, diabetic kidney disease, diabetic foot, and cardiovascular and cerebrovascular diseases, such as ischemic stroke, head injury, history of surgery and cancer; ii) neuropsychiatric disorders, autoimmune diseases, severe anxiety and depression; and iii) non-compliant patient. 
The present study was approved by the ethics committee of Yantai Affiliated Hospital of Binzhou Medical University. Informed consent was obtained from the patients or their families. There were 17 males and 13 females in group A; average age of $70.5 \pm 6.3$; fasting blood sugar averaged $8.2 \pm 2.0 \mathrm{mmol} / 1$; and the course of disease averaged $5.6 \pm 1.7$ years. There were 16 males and 14 females in group B, and the average age was $71.7 \pm 6.5$. There were 15 males and 15 females in group $\mathrm{C}$; average age of $71.6 \pm 6.8$; fasting blood sugar averaged $8.5 \pm 2.2 \mathrm{mmol} / \mathrm{l}$; and the course of disease averaged $5.8 \pm 1.4$ years. There were 16 males and 14 females in group $\mathrm{D}$, and the average age was $71.5 \pm 6.3$. The difference in gender and age among groups was not statistically significant $(\mathrm{P}>0.05)$.

Study methods. We utilized the ELISA method to test the levels of serotonin IGF-1, A $\beta$ and the phosphorylation of immunohistochemistry staining microtubule associated protein (tau protein). We utilized the western blot method to test the level of prion protein (PrP), FOXO subfamily protein, p-PI3K and p-Akt. ELISA kits were purchased from Sigma (St. Louis, MO, USA) and the procedures in the manual were followed during testing. The main procedures of the immunohistochemical (SP) staining method were producing peripheral mononuclear cells of paraffin through conventional steps, including dewaxing, gradient alcoholic dehydration, $3 \% \mathrm{H}_{2} \mathrm{O}_{2}$ inactivation of peroxidase, antigen retrieval, closure, adding phosphorylated tau protein (pSer202) antibody (1:100; Wuhan Boster Biological Engineering Co., Ltd., Wuhan, China), negative control plus phosphate-buffered saline (PBS), at $4^{\circ} \mathrm{C}$ overnight, 5 times of 3 -min PBS washing, adding biotin-marked antibody (Beijing ZS-Bio Co., Ltd., Beijing, China), 30-min at $37^{\circ} \mathrm{C}$ incubation, 5 times of 3-min PBS washing, DAB coloration, hematoxylin staining, conventional dehydration, transparency made by xylene, neutral balsam mounting, observation and capturing images under a microscope (Olympus, Tokyo, Japan). We continuously observed 3 sections, counted 4 non-overlap horizons randomly $<400$-fold enlarged horizon, and tested the ratio of the number of cells with positive response, which was stained pale brown, in each horizon. The averages were determined by using the Image-Pro Plus v6.0 image analysis system.

Western blot analysis involved extraction of general protein by conventional protein extraction kit (CWbio Co., Ltd., Beijing, China), BCA protein quantitation kit (Beijing ZS-Bio Co., Ltd.) testing, polyacrylamide gel electrophoresis (separation gel, stacking gel buffer, Beijing ZS-Bio Co., Ltd.), transmembrane (PVDF film; Millipore Corp., Billerica, MA, USA), closure, antibody incubation (first antibody is rabbit anti-rat PrP 1:2,000; FOXO 1:2,000; p-PI3K 1:1,000; p-Akt 1:1,000; GAPDH 1:500; second antibody is HRP-marked goat anti-rabbit, 1:500), developing and fixing, scanning and analyzing band density by using gel image analysis software, expressing relative content of target protein by using the ratio of target band and relevant GAPDH band signal intensity. The test was repeated 3 times and the average was calculated.

Statistical analysis. SPSS 19.0 software (SPSS, Inc., Chicago, IL, USA) was utilized to analyze the data. Mean \pm standard deviation was used to represent the quantitative data and comparisons among various groups were analyzed by one-way
Table I. Comparison of the level of IGF-1 and A $\beta$.

\begin{tabular}{lcc}
\hline Group & IGF-1, ng/ml & $\mathrm{A} \beta, \mathrm{pg} / \mathrm{ml}$ \\
\hline A & $160.3 \pm 42.1$ & $268.7 \pm 78.5$ \\
B & $113.4 \pm 34.6$ & $184.7 \pm 62.3$ \\
C & $94.7 \pm 25.8$ & $105.6 \pm 41.4$ \\
D & $82.6 \pm 20.3$ & $112.5 \pm 50.6$ \\
F-value & 10.325 & 22.624 \\
P-value & $<0.001$ & $<0.001$ \\
\hline
\end{tabular}

Group A, senior patients with diabetes and dementia; group B, senior patients with dementia but no diabetes; group $\mathrm{C}$, senior patients with diabetes but no dementia; group $\mathrm{D}$, healthy seniors. IGF-1, insulin-like growth factor-1; $A \beta, \beta$-amyloid peptide.

ANOVA, while the qualitative data were expressed by the number of cases, and inter-group comparison was tested by $\chi^{2} . P<0.05$ was considered to indicate a statistically significant difference.

\section{Results}

Comparison of the level of serum IGF-1 and A $\beta$. The levels of IGF-1 and A $\beta$ in group A were significantly higher than that in group $\mathrm{B}$, which was significantly higher than that in groups $\mathrm{C}$ and $\mathrm{D}(\mathrm{P}<0.05)$. The differences between groups $\mathrm{C}$ and $\mathrm{D}$ were not statistically significant $(\mathrm{P}>0.05$; Table I).

Comparison of tau protein phosphorylation level. The tau protein positive rate of group A was $75.6 \pm 20.3 \%$, which was significantly higher than that of group B, $46.9 \pm 15.6 \%$, which was significantly higher than that of groups $\mathrm{C}$ and $\mathrm{D}$, $12.3 \pm 5.5$ and $10.8 \pm 4.7 \%$, respectively. The results were statistically significant $(\mathrm{F}=15.634, \mathrm{P}<0.001)$. The difference between groups $\mathrm{C}$ and $\mathrm{D}$ were not statistically significant $(\mathrm{P}>0.05$; Fig. 1).

Comparison of the level of $\operatorname{Pr} P, F O X$ protein, $p$-PI3K and $p$-Akt. The levels of PrP, FOX protein, p-PI3K and p-Akt of group A were significantly higher that of group $\mathrm{B}$, which were significantly higher than that of groups $\mathrm{C}$ and $\mathrm{D}$, and the results were statistically significant $(\mathrm{P}<0.05)$. The difference between groups $\mathrm{C}$ and $\mathrm{D}$ were not statistically significant $(\mathrm{P}>0.05$; Table II and Fig. 2).

\section{Discussion}

$\mathrm{AD}$ and Creutzfelt-Jakob disease (CJD) are neurodegenerative diseases that are caused by conformational change which result from the abnormal protein folding. In these diseases, normal and solvable protein transfers to unsolvable protein aggregation. In $\mathrm{AD}$, this results in $\mathrm{A} \beta$ protein deposition and in CJD, this results in proteinase $\mathrm{K}$ resistant prion protein (PrPSc) deposition (6). It has been found that PrPs play an important role in the process where $\mathrm{A} \beta$ triggers $\mathrm{AD}(7)$. PrP, a highly conserved protein in animals, is highly expressed in 
Table II. Comparison of the level of PrP, FOX protein, p-PI3K and p-Akt.

\begin{tabular}{lcccr}
\hline Group & PrP & FOXO & p-PI3K & p-Akt \\
\hline A & $0.63 \pm 0.07$ & $0.74 \pm 0.08$ & $0.82 \pm 0.06$ & $0.76 \pm 0.05$ \\
B & $0.44 \pm 0.05$ & $0.48 \pm 0.06$ & $0.53 \pm 0.07$ & $0.50 \pm 0.06$ \\
C & $0.18 \pm 0.03$ & $0.20 \pm 0.04$ & $0.21 \pm 0.05$ & $0.19 \pm 0.04$ \\
D & $0.15 \pm 0.03$ & $0.17 \pm 0.03$ & $0.16 \pm 0.04$ & $0.15 \pm 0.03$ \\
F-value & 9.637 & 8.457 & 13.265 & 11.527 \\
P-value & $<0.001$ & $<0.001$ & $<0.001$ & $<0.001$
\end{tabular}

PrP, prion protein; FOX, forkhead box.
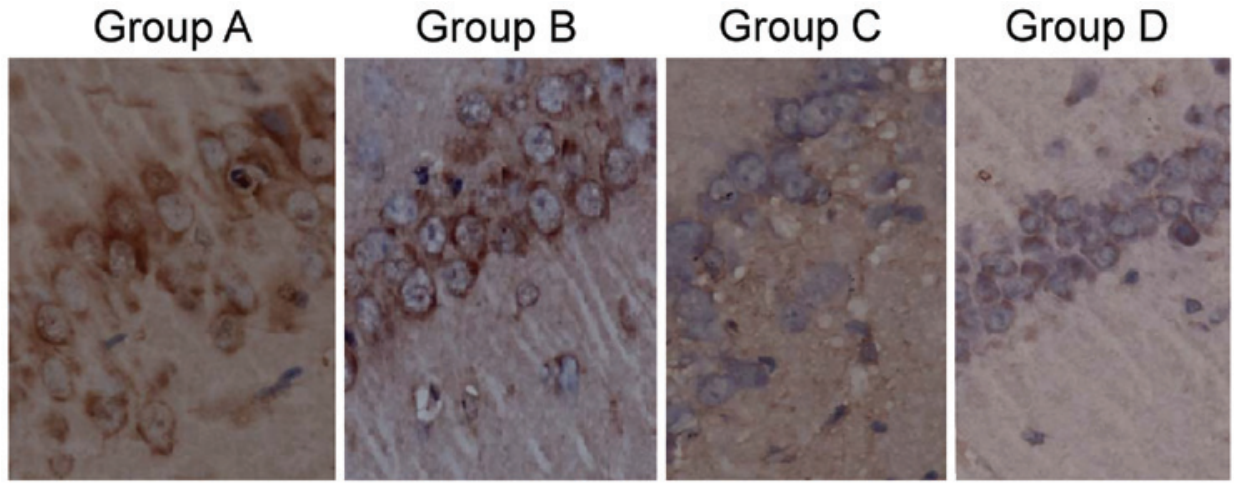

Figure 1. Immunohistochemical staining of tau protein (magnification, $\mathrm{x} 400$ ).

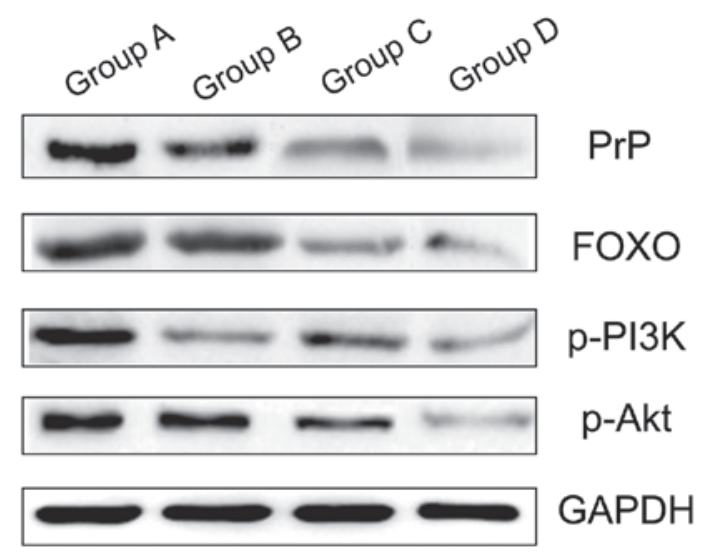

Figure 2. Western blot analysis. PrP, prion protein; FOX, forkhead box.

the nervous system. In normal conditions, $\mathrm{PrP}$ is glycoprotein coded by the housekeeping gene and located on the surface of cell membranes. The change in natural conformation featuring rich $\alpha$-spiral to the wrong conformation featuring rich $\beta$-folding (that is PrPC transferring to PrPSc) will lead to lethal neurodegenerative diseases such as CJD in mammals. The incidence of AD is accompanied by abnormal protein folding, conformational change, the formation of protein aggregation, and neuronal cell degeneration. Protein aggregation plays an important role in the death of cells (8). Currently, there are two opinions on the impact of $\operatorname{PrP}$ in the incidence of $\mathrm{AD}$ : One is that the PrP, as the membrane-anchored protein, functions as signal molecular receptor and triggers a pathway in the cell leading to toxicity by combining with $A \beta$ oligomer outside the cell (9). The second opinion is that the PrP can impact $A \beta$ formation, and is neuro-protective (10). In fact, the two functions can coexist and function in the body due to the PrP structural features and multi-functions resulted from the complexity of glycosylation.

IGF-1, made up of 70 amino acids and also known as sulphited factor and growth regulator $\mathrm{C}$ is a member of the insulin family. It has the function of stimulating the production, differentiation, migration, survival and metabolism. In recent years, IGF-1 has been found closely related to the central nervous system, especially to AD (11). IGF-1 functions through the IGF-1R, which is prevalent in the body. IGF-1R belongs to receptor tyrosine kinase family and is phosphorylated by IGF-1, which can activate insulin receptor substrate serial and other signal transduction pathways, including mitotic active protein kinase pathway, and PI3K/PKB pathway (12). IGF-1 plays a significant role in $\mathrm{A} \beta$ metabolism and tau protein phosphorylation. Adlerz et al (13) found that by stimulating $\alpha$-secretase, IGF-1 decreased the formation of A $\beta$. Zhang et al (14) utilized PC12 cells and found that by stimulating $\alpha$-secretase, IGF-1 decreased the formation of $A \beta$ and that IGF-1 treatment can significantly decrease $\beta$-secretase (BACE-1) mRNA and protein levels and further decrease the formation of $A \beta$ by using quantitative polymerase chain reaction (PCR) and western blot method for analysis of the results. This process was related to PI3K/Akt and MAPK/ERK1/2 signal pathways 
and the disorders of this signal system are involved in the formation of AD pathology. Wang et al (15) conducted IGF-1 intervention by using $A \beta 25-35$ protein to induce injured PC12 cells to establish a cell model for over-phosphorylated tau proteins and found that IGF-1 can repress apoptosis of A $325-35$-induced PC12 cells and tau protein phosphorylation, the action mechanism of which is activated through the signal transduction pathway.

FoxO family, a transcription factor, is a critical factor in INS/IGF-1 signal pathway. The upstream is adjusted by interconnected pathway of PI3K-PKB and the downstream adjusted target genes are mostly related to cell cycle, apoptosis, aging and metabolism (16).

FoxO phosphorylation/dephosphorylating status is closely related to the transcription adjustment function. FoxO transcription activeness is subjected to adjustment of the complex signal pathway. There are mainly two types of FoxO transcription activeness adjusted by phosphorylation: one is PI3 relying on pathway for phosphorylation adjustment and the other is non-PI3 relying on pathway for phosphorylation adjustment. $\mathrm{PI} 3 \mathrm{~K} / \mathrm{Akt} / \mathrm{FoxO}$ is a verified signal pathway (17). Insulin, IGF-1 and other growth factors combine with tyrosine kinase receptor to activate $\mathrm{PI} 3 \mathrm{~K}$. Then Akt, including protein kinase of Akt family and relevant serum and glucocorticoid, induces the activation of SGK. RT-PCR and northern blot display that FoxO transcription factor is highly expressed in tissues and organs of adults, including in the heart and brain (18). In recent years, the study on FoxO action mechanism has gradually transferred from tumor cells to neuronal cells and it was found that when PI3K/Akt is activated, it can phosphorylate and deacetylate under the control of Sirt1, which enhanced the survival and production of neuronal cells (19). When the PI3K/Akt pathway is repressed, it can dephosphorylate and acetylate under the control of P300, inducing neuronal cell apoptosis (20). Dick and Bading (21) reported that the neuronal cells in CA1 area of hippocampus in particular is extremely prone to damage, which is related to the highly expressed FoxO transcription factors in CA1 area (21).

It is concluded from the present study that the level of IGF-1 and $A \beta$, tau protein positive rate, and the level of PrP, FOXO protein, $\mathrm{p}-\mathrm{PI} 3 \mathrm{~K}$ and $\mathrm{p}$-Akt of group $\mathrm{A}$ is significantly higher than that of group B, which is higher than that of groups $\mathrm{C}$ and $\mathrm{D}$, and the results are statistically significant. The difference between groups $\mathrm{C}$ and D is not statistically significant. In summary, IGF-1 is highly expressed in senior patients with diabetes and dementia and it can adjust the expression of PrP and FOXO through p-PI3K/Akt pathway and further impact the formation of $\mathrm{A} \beta$ and tau protein, leading to dementia.

\section{References}

1. Verdelho A, Madureira S, Moleiro C, Ferro JM, Santos CO, Erkinjuntti T, Pantoni L, Fazekas F, Visser M, Waldemar G, et al; LADIS study: White matter changes and diabetes predict cognitive decline in the elderly: The LADIS study. Neurology 75 : $160-167,2010$

2. Rasgon $\mathrm{N}$ and Jarvik L: Insulin resistance, affective disorders, and Alzheimer's disease: Review and hypothesis. J Gerontol A Biol Sci Med Sci 59: 178-183, discussion 184-192, 2004.
3. Freude S, Schilbach K and Schubert M: The role of IGF-1 receptor and insulin receptor signaling for the pathogenesis of Alzheimer's disease: From model organisms to human disease. Curr Alzheimer Res 6: 213-223, 2009.

4. White MF: Regulating insulin signaling and beta-cell function through IRS proteins. Can J Physiol Pharmacol 84: 725-737, 2006.

5. Jeong HJ, Jeong HW, Song SS, Kang JW, Seo JH, Lee YH, Lee KS and Kim DW: Upregulation of peroxiredeoxin III in the hippocampus of acute immobilization stress model rats and the Foxo3a-dependent expression in PC12 cells. Cell Mol Neurobiol 31: 1041-1046, 2011.

6. Zhao WQ, De Felice FG, Fernandez S, Chen H, Lambert MP, Quon MJ, Krafft GA and Klein WL: Amyloid beta oligomers induce impairment of neuronal insulin receptors. FASEB J 22: 246-260, 2008

7. Roychaudhuri R, Yang M, Hoshi MM and Teplow DB: Amyloid beta-protein assembly and Alzheimer disease. J Biol Chem 284: 4749-4753, 2009.

8. Haass C and Selkoe DJ: Soluble protein oligomers in neurodegeneration: Lessons from the Alzheimer's amyloid beta-peptide. Nat Rev Mol Cell Biol 8: 101-112, 2007.

9. Bate $C$ and Williams A: Amyloid- $\beta$-induced synapse damage is mediated via cross-linkage of cellular prion proteins. J Biol Chem 286: 37955-37963, 2011.

10. Cramer PE, Cirrito JR, Wesson DW, Lee CY, Karlo JC, Zinn AE, Casali BT, Restivo JL, Goebel WD, James MJ, et al: ApoE-directed therapeutics rapidly clear $\beta$-amyloid and reverse deficits in AD mouse models. Science 335: 1503-1506, 2012.

11. Deochand C, Tong M, Agarwal AR, Cadenas E and de la Monte SM: Tobacco smoke exposure impairs brain insulin/IGF signaling: Potential co-factor role in neurodegeneration. J Alzheimers Dis 50: 373-386, 2015.

12. Moloney AM, Griffin RJ, Timmons S, O'Connor R, Ravid R and O'Neill C: Defects in IGF-1 receptor, insulin receptor and IRS-1/2 in Alzheimer's disease indicate possible resistance to IGF-1 and insulin signalling. Neurobiol Aging 31: 224-243, 2010.

13. Adlerz L, Holback S, Multhaup G and Iverfeldt K: IGF-1-induced processing of the amyloid precursor protein family is mediated by different signaling pathways. J Biol Chem 282: 10203-10209, 2007.

14. Zhang H, Gao Y, Dai Z, Meng T, Tu S and Yan Y: IGF-1 reduces BACE-1 expression in PC12 cells via activation of PI3-K/Akt and MAPK/ERK1/2 signaling pathways. Neurochem Res 36: 49-57, 2011

15. Wang PJ, Zhang Y, Song RR and Shen DF: Study of the protection and mechanism of IGF-1 on tau protein hyperphosphorylation in PC12 cells induced by Abeta(1-40). Sichuan Da Xue Xue Bao Yi Xue Ban 41: 960-964, 2010 (In Chinese).

16. Puig O, Marr MT, Ruhf ML and Tjian R: Control of cell number by Drosophila FOXO: Downstream and feedback regulation of the insulin receptor pathway. Genes Dev 17: 2006-2020, 2003.

17. Kim SJ, Winter K, Nian C, Tsuneoka M, Koda Y and McIntosh $\mathrm{CH}$ : Glucose-dependent insulinotropic polypeptide (GIP) stimulation of pancreatic beta-cell survival is dependent upon phosphatidylinositol 3-kinase (PI3K)/protein kinase B (PKB) signaling, inactivation of the forkhead transcription factor Foxol, and down-regulation of bax expression. J Biol Chem 280: 22297-22307, 2005.

18. Accili D and Arden KC: FoxOs at the crossroads of cellular metabolism, differentiation, and transformation. Cell 117: 421-426, 2004.

19. Zhao X, Gan L, Pan H, Kan D, Majeski M, Adam SA and Unterman TG: Multiple elements regulate nuclear/cytoplasmic shuttling of FOXO1: Characterization of phosphorylation- and 14-3-3-dependent and -independent mechanisms. Biochem J 378: 839-849, 2004

20. Brunet A, Sweeney LB, Sturgill JF, Chua KF, Greer PL, Lin Y, Tran H, Ross SE, Mostoslavsky R, Cohen HY, et al: Stress-dependent regulation of FOXO transcription factors by the SIRT1 deacetylase. Science 303: 2011-2015, 2004.

21. Dick O and Bading H: Synaptic activity and nuclear calcium signaling protect hippocampal neurons from death signal-associated nuclear translocation of FoxO3a induced by extrasynaptic N-methyl-D-aspartate receptors. J Biol Chem 285: 19354-19361, 2010. 